\title{
A Study on Stator Design for Electromagnetic Noise Reduction in Washing Machine Motor
}

\author{
Kwangsoo Kim \\ Professor, Department of Mechatronics Engineering, Halla University, Wonju, Korea, 26404 \\ kwangsoo2.kim@halla.ac.kr
}

Article History:Received:11 november 2020; Accepted: 27 December 2020; Published online: 05 April 2021 Abstract : For low cost, spoke type ferrite magnet motors with small air gap are using to washing machine. At that time, a
noise problem occurs, so a design to reduce the noise is required. In the washing machine, set noise increased due to the
reduction of air gap of motor at high speed spin mode. Not only the overall noise, but also the harmonics noises are greatly
increased at set. As a result of set noise test and noise analysis through finite elements method, a stator tooth shoe shape in
which the magnetic flux changes rapidly is cause of noise. Its shape creates many harmonics of load torque. The harmonics
component of the load torque increases the overall noise of the set. The harmonics noise of the set has a large correlation
with radial force component as well as the torque ripple. Especially, it is found that the harmonics noise of the set is related
to harmonics component of load torque and the harmonics component of the radial force at stator tooth. The noise is reduced
by applying the new design of stator tooth shoe that can minimize the change in magnetic flux through the noise cause
analysis. Through this research, the harmonics noise as well as overall noise are reduced at small airgap motor. Therefore, it
is possible to develop cost reduction motor for washing machine.

Keywords: Spork type permanent magnet synchronous motor (SPMSM), Radial force, Stator Tooth Shoe, Design, Finite Elements Method, Cost Reduction, Harmonics noise.

\section{Introduction}

Recently, due to high power density and low cost, many studies have been conducted on the SPMSM [1-5]. IPM motor type motors such as these SPMSM has disadvantage for noise. Because low noise as well as low cost is a very important development factor in home application [6]. Therefore, noise reduction is an important issue in design of SPMSM at washing machine. Then, cost savings in washing machines using SPMSM require airgap reduction and stack length reduction for same performance. In this case, noise problem is occurred.

In the case of washing machine motors, there are two modes of operation: washing mode and spin(dehydration) mode, and the mode in which noise is more important is spin mode. When washing mode, most of the noise is made due to rotation of laundry and water, but during the spin mode, noise of basket rotation is the main noise. The main noise source for spin mode is motors. The causes of noise in motors are being studied a lot [6-8]. The causes of noise are closely related to the shape of the shoe of stator tooth [9].

In this paper, we analyze the relationship between set noise and motor shoe shape. In addition, a new shape of the shoe is proposed through the analysis of the relationship with the representative noise sources, and the noise of the washing machine during spin mode is reduced through the optimal design.

\section{Low cost and low noise SPMSM design}

Generally, causes of motor noise and vibration are cogging torque, torque ripple, and radial force [10-12]. Among them, the radial force in this paper represents the radial force at the stator tooth. As shown in figure 1, it is based on the integrated value using the maxwell stress tensor in the line below the stator shoe. The formula for radial force is as follows [13].

$$
f=\frac{1}{\mu_{0}}\left(B_{n}-B_{t}\right)
$$

where $\mathrm{f}$ is radial force, $\mathrm{B}_{\mathrm{n}}$ is normal component of airgap flux density, $\mathrm{B}_{\mathrm{t}}$ is tangential component of airgap flux density.

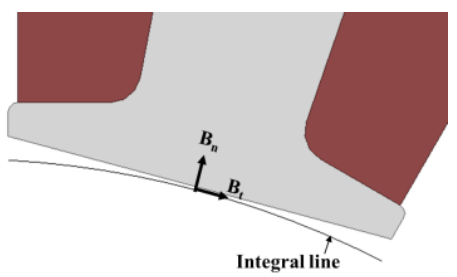

Figure 1. Calculation line of radial force at stator tooth

There are the noises of two mode in the washing machine. The noise of the machine is important both in the washing mode and spin mode. Both noises in both modes are related to cogging torque, torque ripple, radial force as shown in figure 2. However, the degree of association is different for each mode. According to the load and speed, the noise in the spin mode is related to torque ripple and radial force, the noise in the washing mode

*Corresponding author: Kwangsoo Kim 
is related to cogging torque and the radial force.

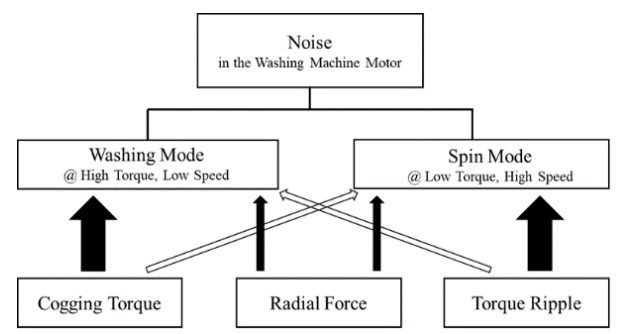

Figure 2. Noise in the washing machine and relationships of noise factors

\section{Small airgap motor noise test and analysis}

The existing washing machine motor is 8 pole, 12 stator slots and spoke type model. To reduce cost, stack length of the model is lower. And airgap is smaller for the same performance compared to the existing model. First, reduced airgap model is designed to have same performance as the design objective.

Set noise test is performed on the new motor with small airgap and the existing motor using washing machine. The noise of the motor at the high speed of spin mode, low load is more important, so the noise test is carried out based on this mode.

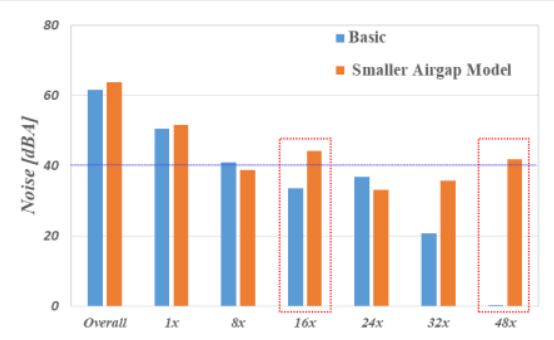

Figure 3. Noise Test Result of Basic Motor \& Small airgap Motor (1st Design Model)

The objectives of the noise in this design are overall noise equivalence level, and the harmonics noise levels are below 40dBA. After noise test at spin mode, overall noise, 8x, 16x, 32x, 48x harmonics noises are represented in figure 3. Compared to existing model, overall noise level and harmonics noises are increase. Especially, harmonics noise $16 \mathrm{x}$ and $48 \mathrm{x}$ is more than $40 \mathrm{dBA}$. Therefore, 16x and 48x harmonics is needs to reduce at re-design of reducing noise.

At the initial design, multi-stage stator shoe design was applied to satisfied with same performance. Figure 4 represents tooth shoe shape and torque ripple according to the step shape. As shown in figure 4, the harmonics of torque ripple are greatly increased due to the sudden flux change in each step. So, overall noise and harmonics noises increase.

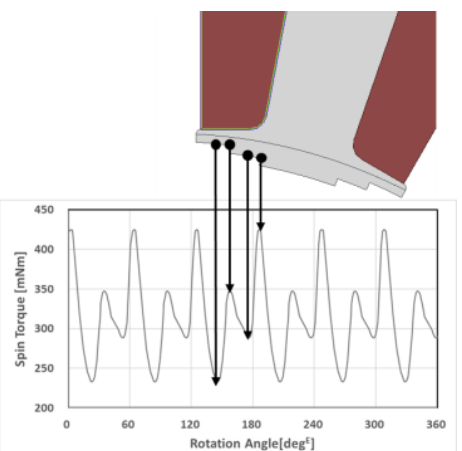

Figure 4. Spin torque ripple according to stator tooth shoe shape

Next, analysis of noise of $16 x$ and $48 x$ noise for set is performed. Figure 5 represents set 16x harmonics noise is proportional to $16 \mathrm{x}$ harmonics of tooth radial force and set $48 \mathrm{x}$ harmonics noise is proportional to $48 \mathrm{x}$ harmonics spin torque. This analysis of the correlation between the set noise and the noise of motor informs that harmonics noises of the motor are expressed as the harmonics noises of the set as shown in figure 5. Therefore, the size of harmonics components of load torque, radial force should be minimized using the noise reduction design. 

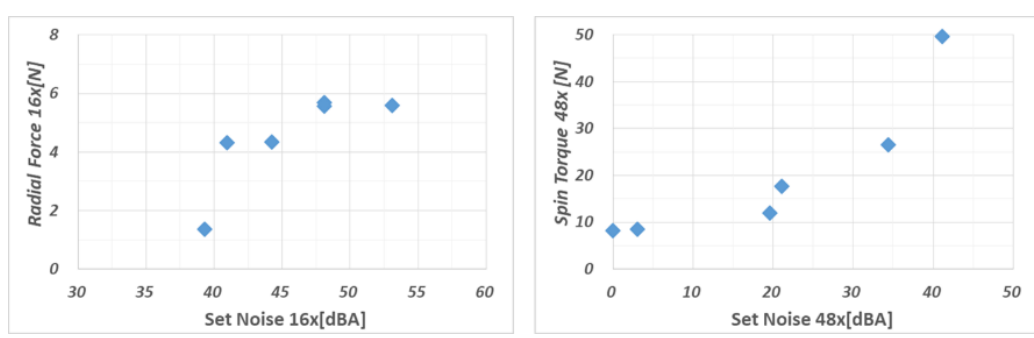

Figure 5. The relation between Set noise and Radial Force/Spin Torque

\section{New design of stator tooth shoe}

It is difficult to decrease the harmonics of load torque in the multi-stage structure as shown in figure 4.

Therefore, a new structure that minimizes flux change is needed. The new shape of tooth shoe shown in figure 6 reduce spin torque harmonics due to changing flux smoothly. And figure 6 shows that parameters are presented for stator tooth shoe design for noise reduction. The existing three stage multi-stage structure is divided into five parameters to minimize flux change.

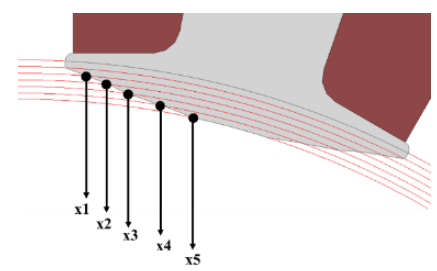

Figure 6. New design shape of tooth shoe using 5 level design parameters

Using five parameters, re-design that satisfies the same performance and minimizing torque ripple and cogging torque is performed through parametric analysis. In this design, the final model is selected using three maps emf, radial force $16 \mathrm{x}$ and spin torque $48 \mathrm{x}$ as shown in figure 7.

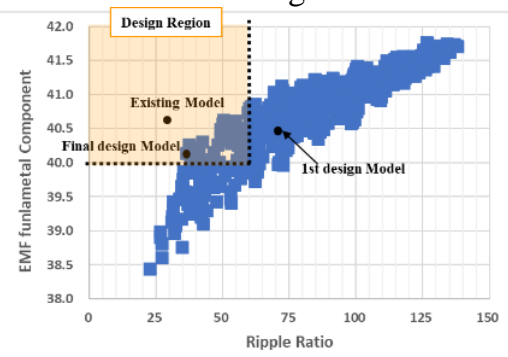

(a) Design region at EMF and ripple ratio graph

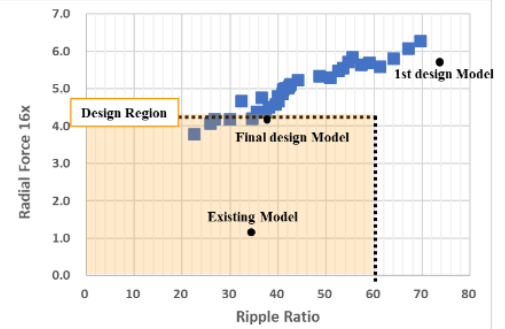

(b) Design region at radial force 16x and ripple ratio graph

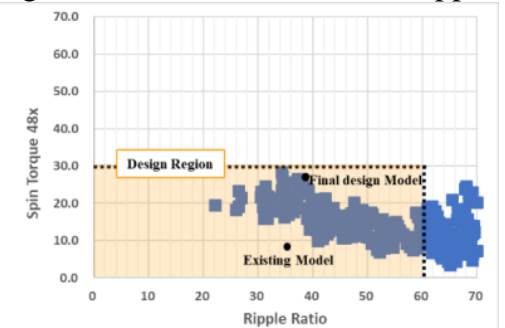

(c) Design region at Spin Torque 48x and ripple ratio graph Figure 7. Design map using parameter analysis result

Table 1: Comparison of final model analysis 


\begin{tabular}{|c|c|c|c|}
\hline Item & Existing Model & $\begin{array}{c}1^{\text {st }} \text { small airgap } \\
\text { Model }\end{array}$ & Final Model \\
\hline EMF Value & 40.6 & 40.4 & 40.1 \\
\hline Torque ripple ratio & 34 & 74 & 4 \\
\hline Radial force 16x & 1.2 & 5.8 & 26 \\
\hline Spin Torque 48x & 8.3 & 31 & 4 \\
\hline
\end{tabular}

First the performance indicators are determined by magnitude of the fundamental emf. And set 16x harmonics noise is examined based on the 16th of radial force of tooth. Last, set $48 x$ harmonics noise is examined based on the 48th of spin torque. Here, each limit values are selected through set tests under various conditions. And, because it is difficult to analyze the exact same torque, the ripple ratio is used as a reference for the amplitude of torque ripple. Here, ripple ratio is ratio of average toque and torque ripple as shown in the formula (2).

$$
\text { ripple ratio }=\frac{\text { Average Torque }}{\text { Amplitude of torque ripple }}
$$

The final model satisfying the three design maps is selected in Figure 7. The final design model's analysis result value is shown in Table 1. Through this design method, the final model has a higher noise level than the existing model with large airgap, but is improved compared to the first model, and all limit values are satisfied.

Figure 8 represent the comparison of torque ripple between first design model and final design models. According to shape of stator tooth shoe design, harmonics as well as amplitude of torque ripple can be reduced.

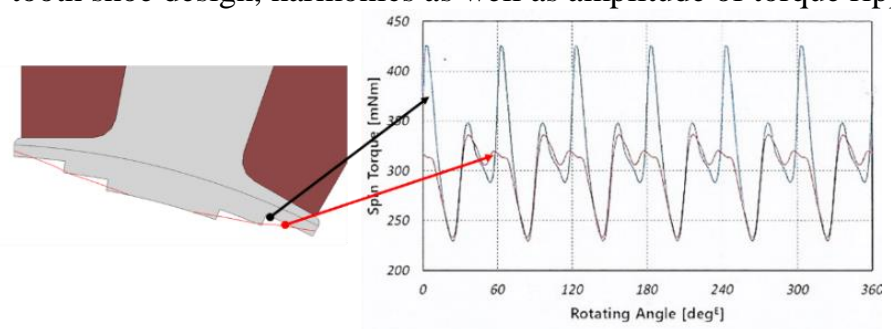

Figure 8. Torque ripple according to shape of stator tooth shoe

\section{Verification}

The finite element analysis confirmed that the performance and noise conditions were satisfied. The final model is verified by the actual SET noise test. Figure 9 represents the assembled motor to the set for measuring the set noise. Motor connected to set using belt. 3 Microphones (Front, Left, Right) are located 1m away from set.

As shown in Figure 10, the set test results show that the overall noise level achieved the same level of existing motors. And the harmonics noises of 16x and 48x, which were the initial problems, meet noise reference.
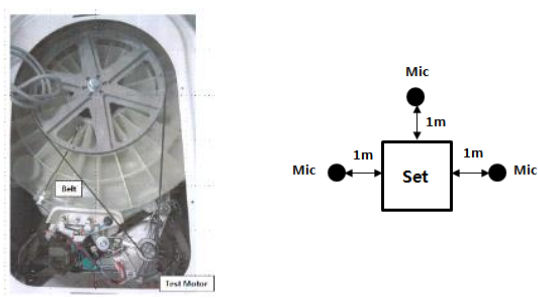

Figure 9. Setting of set noise test 


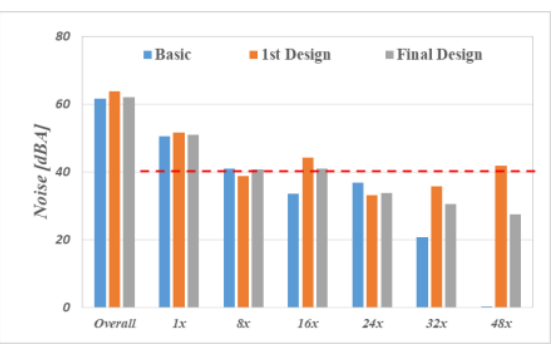

\section{Conclusion}

Figure 10. Noise test result of final motor

This paper analyzes the causes of noise for cost reduction design of SFMSM motors used in washing machine and the noise reduction studies is conducted through the design of stator tooth shoe. The final noise reduction model was verified through the set noise test. Here, it was verified that the shape of the shoe had a great influence on the noise, and it was found that the harmonics noise of washing machine can reduce by reducing the harmonics noise of motor. In various application, this noise analysis and reduction method can be used in noise reduction design by analyzing the noise component of the set and reducing the corresponding noise component of motor.

\section{Acknowledgements}

This work was supported by the National Research Foundation of Korea (NRF) grant funded by the Korea government (MSIP; Ministry of Science, ICT \& Future Planning) (No. NRF-2018R1C1B5085711)

\section{References}

1. Sung-Il Kim, Sunghyuk Park, Taesang Park, Jinwoo Cho, Wonho Kim, Seongtaek Lim. (2014) Investigation and Experimental Verification of a Novel Spoke-Type Ferrite-Magnet Motor for ElectricVehicle Traction Drive Applications. IEEE Transactions on Industrial Electronics 61(10), 5763-5770

2. Hyun-Soo Seol, Tea-Chul Jung, Hyun-Woo Jun, Ju Lee, Dong-Woo Kang. (2017) Design of 3-Times Magnetizer and Rotor of Spoke-Type PMSM Considering Post-Assembly Magnetization. IEEE Transactions on Magnetics (11), Art. ID 8208005.

3. Sung Gu Lee, Ju Lee, Won-Ho Kim. (2017) A Study on Correcting the Nonlinearity Between Stack Length and Back Electromotive Force in Spoke Type Ferrite Magnet Motors. IEEE Transactions on Magnetics 53(6), Art. ID 8201404.

4. Enrico Carraro, Nicola Bianchi, Sunny Zhang, Matthias Koch. (2018) Design and Performance Comparison of Fractional Slot Concentrated Winding Spoke Type Synchronous Motors With Different Slot-Pole Combinations. IEEE Transactions on Industry Applications 54(3), 2276-2284

5. Sung Gu Lee, Jaenam Bae, Won-Ho Kim. (2020) Design Process of Spoke-Type Permanent Magnet Synchronous Motor Considering Magnetization Performance. IEEE Transactions on Applied Superconductivity, 30(4), Art. ID 5205706

6. S.-M. Hwang, H.-J. Lee, T.-S Kim, Y.-H Jung, J.-P. Hong. (2006) The Influence of Electromagnetic Force Upon the Noise of an IPM Motor Used in a Compressor. IEEE Transactions on Magnetics 42(10), 34943496

7. Mohammad S. Islam, Rakib Islam, Tomy Sebastian. (2014) Noise and Vibration Characteristics of Permanent-Magnet Synchronous Motors Using Electromagnetic and Structural Analyses. IEEE Transactions on Industry Applications 50(5), 3214-3222

8. Shuguang Zuo, Fu Lin, Xudong Wu. (2015) Noise Analysis, Calculation, and Reduction of External Rotor Permanent-Magnet Synchronous Motor. IEEE Transactions on Industrial Electronics 62(10), 6204-6212

9. Sang-Moon Hwang, Jae-Boo Eom, Geun-Bae Hwang, Weui-Bong Jeong, Yoong-Ho Jung. (2000) Cogging torque and acoustic noise reduction in permanent magnet motors by teeth pairing. IEEE Transactions on Magnetics 35(5), 3144-3146

10. Z.Q. Zhu, Y. Liu, D. Howe. (2006) Minimizing the Influence of Cogging Torque on Vibration of PM Brushless Machines by Direct Torque Control. IEEE Transactions on Magnetics 42(10), 3512-3514

11. Sung-Il Kim, Ji-Young Lee, Young-Kyoun Kim, Jung-Pyo Hong, Y. Hur, Yeon-Hwan Jung. (2005) Optimization for reduction of torque ripple in interior permanent magnet motor by using the Taguchi method. IEEE Transactions on Magnetics 41(5), 1796-9

12. Alan Dorneles Callegaro, Jianbin Liang, James Weisheng Jiang, Berker Bilgin, Ali Emadi. (2019) Radial Force Density Analysis of Switched Reluctance Machines: The Source of Acoustic Noise. IEEE Transactions on Transportation Electrification 5(1), 93-106

13. E.C.T. So, S.J. Yang. (1993) The effect of tooth shape on radial forces in step motors. IEEE Transactions on Magnetics 29(6), 2413-5 